УДК 330.4:519.86

Т. О. Прокопенко, д.т.н., доиент,

e-mail: t.prokopenko@chdtu.edu.ua

О. Б. Обойщик, студент

Черкаський державний технологічний університет

б-р Шевченка, 460, м. Черкаси, 18006, Україна

\title{
ОСОБЛИВОСТІ ВИКОРИСТАННЯ ЧАТБОТІВ ДЛЯ БІЗНЕСУ У СУЧАСНИХ МЕСЕНДЖЕР ЧАТАХ
}

Пропонується аналіз особливостей використання чатботів у сучасних компаніях для вирімення бізнес-задач у прочесі спілкування в сучасних месенджер чатах. Подано визначення чатботів і досліджено їх основні функиії. Розглянуто основні переваги використання технології чатботів для задоволення сучасних потреб бізнесу. Запропоновано узагальнену класифікацію чатботів. Зроблено висновки про можливість та дочільність застосування різних типів чатботів для бізнесу у сучасних чатах обміну миттєвими повідомленнями.

Ключові слова: чатбот, бот, месенджер чат, итучний інтелект, потреби бізнесу, класифікаиія.

Вступ. Питанню застосування чатботів для задоволення бізнес-потреб приділяється особливо гостра увага впродовж багатьох років. Сьогодні використання чатботів для забезпечення віртуального спілкування бізнесу зі своїми потенційними та існуючими користувачами $\epsilon$ актуальною задачею, що надасть можливості швидкого обміну інформацією між бізнесом і клієнтами в сучасних месенджер чатах для розв'язання будь-яких питань консультування, можливості одночасного обслуговування десятків тисяч клієнтів, доступності бізнесу 24/7 та інших переваг [14].

Для різних компаній, що існують у бізнес-середовищі, важливим є своєчасне та швидке забезпечення користувачів необхідною інформацією. Саме тут у нагоді стає технологія чатботів, яку багато експертів вважають майбутнім сфери обслуговування та управління клієнтами [11].

Для розв'язання цих питань необхідним $є$ визначення самого поняття чатбота та огляд класифікації існуючих ботів, основних функцій, які вони виконують, і принципів роботи чатботів у месенджер чатах на основі імітації мовної поведінки людини у процесі спілкування зі споживачами.

Аналіз останніх досліджень та публікацій. Використання штучного інтелекту на сьогоднішній день все більше знаходить своє застосування у вигляді чатботів, що стають доступними для клієнтів бізнесу різного типу через сучасні месенджер чати, якими щоденно користуються мільйони людей по всьому світу. Наразі все актуальнішою проблемою для бізнесу стає побудова та використання чатботів для оптимізації своїх бізнес-процесів i створення умов цілодобової онлайнприсутності для обслуговування та консультування своїх клієнтів, а також нагального вирішення їхніх питань без необхідності залучення людських ресурсів, що значно знижує фінансові витрати. Проблеми онлайнкомунікацій між користувачами в Інтернеті, у тому числі за участі віртуального співрозмовника, розглянуто в працях В. А. Михайлова [2], В. А. Плєшакова [3], В. Л. Сілаєвої [4], Г. Д. Ушакова [6]. Особливості застосування чатботів для бізнесу у сучасних месенджерах грунтовно описано в статтях зарубіжних авторів, а саме: Крістен Хейлі [14], Саварама Сутхара [12], Шейна Кетермана [10], Алекса Галерта [8] та інших. Однак для прийняття правильного рішення для розробки та використання чатботів для бізнесу необхідно визначити основну мету і сукупність завдань для розв'язання штучним інтелектом, щоб обрати необхідний вид чатбота для задоволення нагальних потреб.

Метою статті $\epsilon$ аналіз основних функцій чатбота, дослідження можливостей використання різних видів чатботів для бізнесу у чатах обміну миттєвими повідомленнями.

Викладення основного матеріалу дослідження. Розвиток методів і засобів штучного інтелекту разом з поширенням додатків для 
обміну миттєвими повідомленнями, або ж месенджер чатів, забезпечили можливість створення чатботів. Чатботи є програмою, що використовує обмін повідомленнями як інтерфейс, через який можна виконувати будь-яку кількість завдань, і яка здатна відповідати на питання користувачів, а також самостійно ставити їх, таким чином підтримуючи діалог, імітуючи мовну поведінку справжньої людини. Чатботи використовують у різних сферах для розв'язання типових задач, зокрема в різних компаніях для вирішення бізнес-задач. Використання чатботів є особливо доцільним при застосуванні мобільних пристроїв, в яких обмін повідомленнями є основою мобільного досвіду, що широко застосовується користувачами $з$ усього світу $[1,17]$.

Залежно від функцій, що реалізуються, чатботи прийнято поділяти на три основні типи [1]:

- службові - автоматизовані програми, призначені для виконання допоміжних завдань, таких як облік учасників чату, гарантування безпеки учасників чату, підключення додаткових функцій у разі застосування певної команди тощо;

- інформаційно-розважальні - автоматизовані програми, що імітують мовну поведінку людини і виконують інформаційну, комерційну або розважальну функції, наприклад бот, що повідомляє користувачам прогноз погоди, бот-гра, бот, який здійснює продаж певного товару;

- боти-утиліти - автоматизовані сервісні програми, які полегшують користування іншими програмами, наприклад ботперекладач, бот-калькулятор.

Залежно від способу програмування конкретні боти пропонується поділити на дві великі групи [15]:

- скриптові чатботи, які працюють за попередньо підготовленими командами або скриптами. Тобто під час розмови 3 цим типом чатботів користувачеві потрібно вибрати одну 3 запропонованих опцій на кожному кроці спілкування, для того щоб визначити наступний крок;

- розумні чатботи, що побудовані за допомогою можливостей штучного інтелекту. Замість підготовлених відповідей, такий чатбот відповідає пропозиціям по запропонованій користувачем темі на основі наявної інформації. Штучний інтелект дає можливість таким чатботам бути більш гнучкими за рахунок роз(C) Т. О. Прокопенко, О. Б. Обойщик, 2019 DOI: $10.24025 / 2306-4412.1 .2019 .165418$ пізнавання введеного користувачами текстового висловлювання, а також вдосконалюватися за рахунок постійного навчання моделі.

Згідно 3 [15] експерти в цій галузі розглядають такі функції чатботів:

- забезпечення безперервного функціонування сервісу обслуговування клієнтів;

- персоналізація процесу комунікацій 3 новими та існуючими клієнтами бізнесу;

- впорядкування процесу здійснення покупок користувачами та надання консультацій під час цього процесу;

- автоматизація повторюваних завдань.

Для різних компаній, які хотіли б розширити свій вплив в Інтернеті, чатботи можуть відіграти важливу роль у реалізації істоpiï успіху. Боти можуть використовуватися в усіх бізнес-галузях, де можлива комунікація 3 користувачем. Передбачаючи величезний потенціал, підприємства починають інтенсивно вкладати кошти у розвиток чатботів для власного бізнесу 3 метою автоматизації значної кількості процесів, які раніше виконували співробітники компанії, наприклад консультування. Ряд світових брендів і виробників вже запустили власних ботів у популярних месенджер чатах, включаючи НР, 1-800Flowers та CNN [17]. Велике значення має те, що великі технологічні компанії створили власні відкриті платформи та інтерфейси для розробки чатботів, серед яких Microsoft, Facebook, Google, Amazon, IBM, Apple, Samsung тощо [8].

Такі українські компанії, як Київстар, ПриватБанк, Альфа-Банк, Нова пошта тощо вже мають власних ботів. Чатботи також активно використовуються на порталі Донор.uа, у сервісі реєстрацій компаній bot.lawyer, у сервісі моніторингу реєстраційних даних українських компаній та судового реєстру для захисту від рейдерських захоплень і контролю контрагентів OpenDataBot. Українцями також було розроблено Telegram-бот iGov [5].

Завдяки бізнес-рішенню, яке пропонує технологія чатботів, власникам надається можливість застосовувати технології штучного інтелекту. Крім того, використання якісного чатбота гарантує більш швидку й точну службу підтримки для клієнтів, що підвищить репутацію бренду. Очікується, що незабаром кожний бізнес буде мати власний чатбот. Боти стануть такими ж поширеними, як номери бізнес-телефонів, а 3 більш розвиненими системами штучного інтелекту чатботи зможуть 
повністю замінити людську допомогу у виконанні певних завдань [10].

Однією з основних причин значної популярності чатботів $є$ небажання користувачів завантажувати нові чи оновлені додатки на свої мобільні пристрої, для того щоб користуватися певними послугами. 3 цього випливає, що створювати, просувати і вводити в експлуатацію нову програму, яка зрештою не буде застосована, $є$ неприбутковим. Маючи здатність функціонувати на різних платформах, чатботи можуть вирішити цю проблему. Згідно $з$ даними 2018 State of Chatbots Report від компаніï Drift (рис. 1) загальна кількість користувачів різних месенджер чатів становить 4,1 мільярда людей, тому, використовуючи чатботи в месенджер чатах, бізнес може скористатися наступними перевагами, надзвичайно важливими для споживачів [8]:

- можливість отримання швидкої відповіді на поставлені користувачами питання різного рівня складності;

- функціонування чатботів в режимі 24 години на добу;

- зручність спілкування у месенджер чатах;

- можливість швидко зареєструвати скаргу та отримати зворотний зв'язок;

- доброзичливість, доступність та ін.

\section{Chatbots vs. Apps $\begin{aligned} & \text { Which of these benefits do you most associate } \\ & \text { with communicating with businesses? }\end{aligned}$}
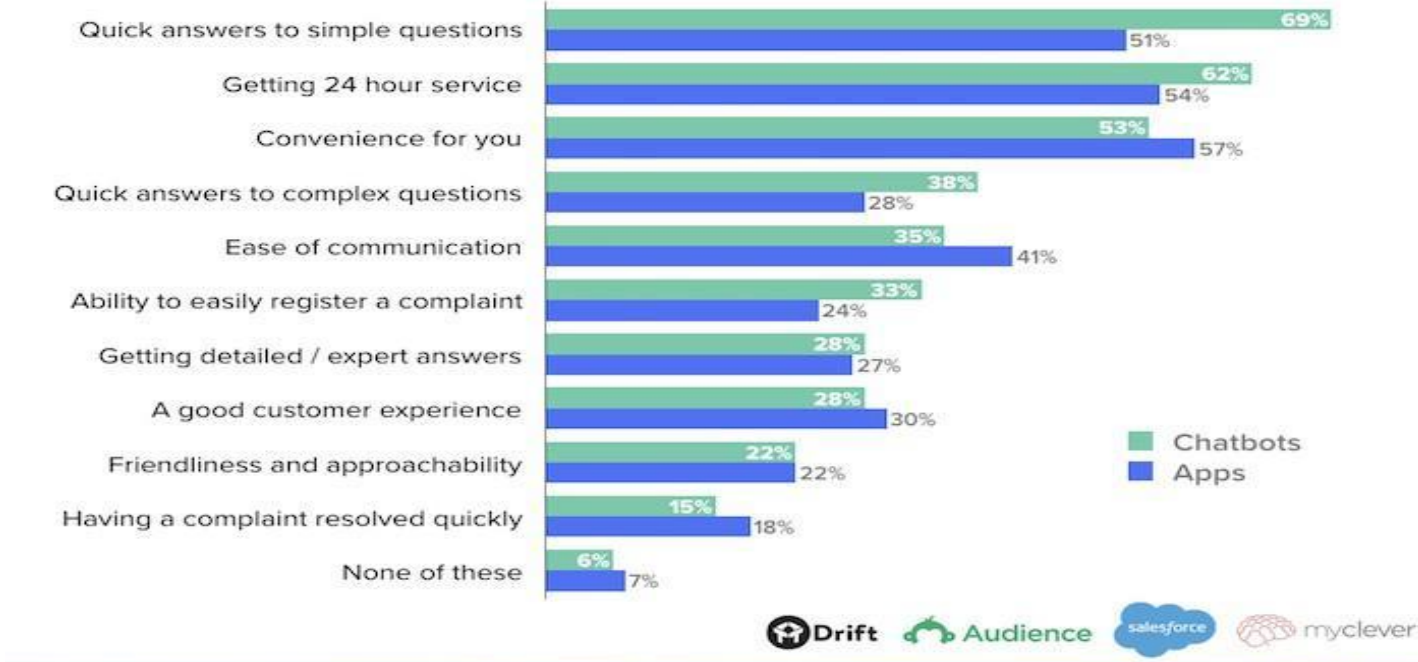

Рисунок 1 - Переваги чатботів над мобільними додатками згідно 32018 State of Chatbots Report від компанії Drift

Використання в бізнесі автоматизованих чатботів може привести до значного скорочення витрат на трудові ресурси. Хоча повна автоматизація роботи служби підтримки клієнтів не $є$ можливою у найближчі роки, проте автоматизація таких процесів, як онлайнпродажі та консультування клієнтів через месенджер чати приведе до оптимізації фінансових ресурсів компанії. Крім того, чатботи дадуть бізнесу можливість позбавити виконавців від виконання рутинних завдань, а величезна швидкість і можливість одночасної обробки мільйонів запитів від користувачів допоможе отримати лояльність споживачів [15].

Чатботи можуть запропонувати цілодобовий інформаційний обмін, надійність, точ- ність і безвідмовну продуктивність. Розвиток ефективного бота приведе до стабільного та постійного вирішення поставлених компанією бізнес-задач. Крім того, чатботи надають користувачам можливості дослідження способів спілкування, що забезпечить аналіз отриманих даних, покращення роботи чатбота в подальшому і побудову надійної бізнес-моделі, яка дасть значну перевагу над існуючими конкурентами.

Наразі існує величезний потенціал у використанні чатботів у різних компаніях для забезпечення швидкого реагування на запити клієнтів. Згідно 3 дослідженнями InsideSales i Harvard Business Review (рис. 2) п'ятихвилинна затримка у відповіді користу- 
вачу може призвести до втрати здійснення користувачем можливої покупки. Затримка у наданні відповіді у десять хвилин зменшить шанси отримати ефективний контакт 3 потенційним споживачем до $400 \%$ [8].

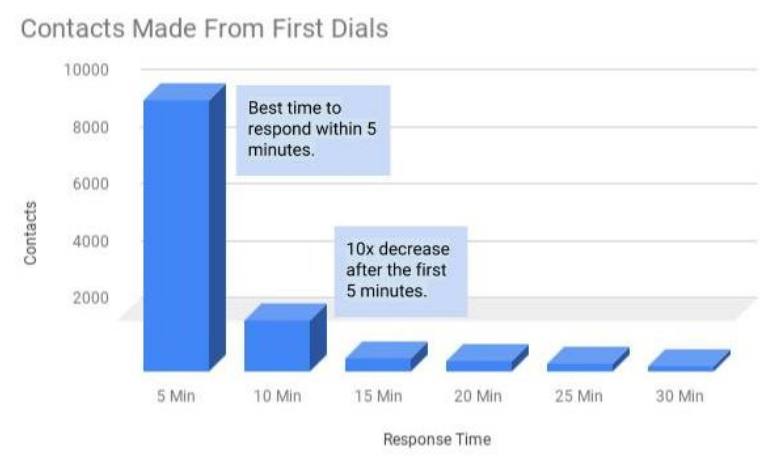

$>$ Contact and qualification rates drop dramatically in just minutes and continue to decrease over the next few hours.

Рисунок 2 - Вплив затримки надання відповіді на ефективність комунікацій 3 користувачами
Таким чином, чатботи є одним із найпростіших способів вирішення задач обміну інформаційними повідомленнями між користувачами, що забезпечить отримання інформації в обмежений часовий термін. Телефонні дзвінки, електронні листи та навіть веб-форми не можуть дозволити надати відповідь користувачам упродовж декількох секунд, на що натомість спроможна сучасна технологія чатботів. Тому, в різних компаніях доцільним $\epsilon$ застосування технології чатботів, що забезпечить можливості швидкого отримання необхідної інформації та вплине на ефективність компанії в цілому.

Проаналізувавши різні підходи до класифікації чатботів, пропонується узагальнена класифікація чатботів, що дасть можливість чіткого визначення способів обміну інформацією з метою ефективного використання часу.

Таблиця 1 - Узагальнена класифікація чатботів

\begin{tabular}{|c|c|c|c|c|c|c|c|}
\hline \multirow{2}{*}{$\begin{array}{c}\text { За способом } \\
\text { програму- } \\
\text { вання }\end{array}$} & \multicolumn{7}{|c|}{ За можливостями застосування } \\
\hline & \multicolumn{3}{|c|}{$\begin{array}{c}\text { за функціями, } \\
\text { що реалізує чатбот }\end{array}$} & \multicolumn{4}{|c|}{ за призначенням } \\
\hline скриптові & \multirow[t]{2}{*}{$\begin{array}{l}\text { служ- } \\
\text { бові }\end{array}$} & \multirow{2}{*}{$\begin{array}{c}\text { інформа- } \\
\text { ційно- } \\
\text { розва- } \\
\text { жальні }\end{array}$} & \multirow[t]{2}{*}{$\begin{array}{c}\text { боти- } \\
\text { утиліти }\end{array}$} & $\begin{array}{l}\text { інформа- } \\
\text { ційно- } \\
\text { пошукові }\end{array}$ & $\begin{array}{l}\text { консуль- } \\
\text { туючі }\end{array}$ & $\begin{array}{l}\text { контро- } \\
\text { люючі }\end{array}$ & $\begin{array}{l}\text { py- } \\
\text { тинні }\end{array}$ \\
\hline розумні & & & & \multicolumn{4}{|c|}{$\begin{array}{c}\text { автоматизовані функції спілкування } \\
\text { з користувачем }\end{array}$} \\
\hline
\end{tabular}

Відомий футуролог Реймонд Курцвейл, який займає посаду технічного директора в сфері машинного навчання і обробки природної мови в компанії Google, прогнозує, що до 2029 р. чатботи будуть володіти такими ж мовними можливостями, як і люди. Саме тоді гостро постане питання працевлаштування людей, більшість професій яких замінить використання чатботів та штучного інтелекту [7].

Висновки. Отримані результати показують, що в різних компаніях важливим $\epsilon$ процес обміну інформаційними повідомленнями 3 метою вирішення різних бізнес-задач, що надасть можливості оптимізації робот компанії. Застосування при цьому технології чатботів та штучного інтелекту, коли «розумні» чатботи, імітуючи мовну поведінку людини, надають можливості для швидкого та постійного обміну інформацією в режимі 24/7 по всьому світу, є актуальним

Згідно 3 дослідженнями першоджерел найдоцільнішими видами ботів для різних типів бізнесу є інформаційно-розважальні ро- зумні боти, які виконують функції співрозмовника-помічника, який в змозі вирішити нагальні потреби користувача в будь-який час і день тижня в режимі онлайн.

Внаслідок проведеного аналізу стає очевидним, що екосистема чатботів значно зросла протягом останнього десятиліття та охоплює безліч видів ботів, розроблених за допомогою різноманітних технологій для популярних в усьому світі чатів обміну миттєвими повідомленнями. Важливо відзначити, що розробка чатбота для бізнесу у будь-якому сучасному месенджер чаті є надзвичайно актуальною для сьогодення на національному та зарубіжному ринках і потребує обробки й аналізу великого обсягу інформації, пов'язаної з цілями, яких бізнес хоче досягнути, створивши цей продукт. Рішення щодо типу та доцільності побудови чатбота завжди приймаються на основі цієї інформації, тому досить важливим $є$ процес отримання необхідної інформації, iї ефективної обробки й аналізу, що полегшує прийняття рішення. Тому запропоновано узагальнену 
класифікацію чатботів, що забезпечить можливості вибору необхідного чатбота для вирішення бізнес-задач і дасть змогу досягнути запланованих результатів для ефективної роботи компанії.

\section{Список літератури}

1. Бот (программа). Материал из Википедии свободной энциклопедии. URL: https://ru.wikipdia.org/wiki/\%D0\%91\%D0\%B E\%D1\%82_(\%D0\%BF\%D1\%80\%D0\%BE\% D0\%B3\%D1\%80\%D0\%B0\%D0\%BC\%D0\% $\mathrm{BC} \% \mathrm{D} 0 \% \mathrm{~B} 0)$

2. Михайлов В. А., Михайлов С. В. Особенности развития информационно-коммуникативной среды современного общества. Актуальные проблемы теории коммуникации: сб. науч. трудов. Санкт-Петербург, 2004. C. 34-52.

3. Плешаков В. А. Киберсоциализация человека в информационном пространстве. Информация и образование: гранищь коммуникаций INFO'2009: сб. науч. трудов. Горно-Алтайск: РИО ГАГУ, 2009. С. 51.

4. Силаева В. Л. Интернет как социальный феномен. Социс: сетевой журн. 2008. № 11. C. 101-107. URL: http://www.isras.ru/files/ File/Socis/2008-11/Silaeva_14.pdf

5. Современные IT технологии для бизнеса: зачем компаниям боты и облака. URL: https://www.epravda.com.ua/rus/publications/ 2017/03/20/622844/

6. Ушакова Г. Д., Балабанова Ю. В. Особенности виртуального общения посредством чатов. Филологический журнал: межвуз. сб. науч. статей. 2004. Вып. XII. С. 59-61.

7. Чатботи - хто вони? URL: http://thefuture. news/chatbot

8. Chatbot report 2018: global trends and analysis. URL: https://chatbotsmagazine.com/ chatbot-report-2018-global-trends-and-analy sis-4d8bbe $4 \mathrm{~d} 924 \mathrm{~b}$

9. Chatbots 101: building a chatbot for business with wells fargo. URL: https://chatbotsjour nal.com/chatbots-101-building-a-chatbot-forbusiness-with-wells-fargo-85ecf03f736d

10.Reasons to have a chatbot for your business. URL: https://chatbotslife.com/reasons-to-ha ve-a-chatbot-for-your-business-59e0c7427cf2

11.The true chatbot superpower for businesses and it's not AI. URL: https://medium.com/@ shanejketterman/chatbot-messaging-is-power ful-ai-is-hype-so-what-is-messaging-ebd0620 c93fb
12.Top 10 platforms to build a chatbot for your business. URL: https://chatbotsmagazine.com/ top-10-platforms-to-build-a-chatbot-for-yourbusiness-6393ed047be7

13.Trending: how to use facebook messenger chatbot for business. URL: https://medium. com/@ kris10haley/trending-how-to-use-face book-messenger-chatbot-for-business-96fe 5 dac 337d

14.V-Soft consulting chatbots 101. URL: https://cdn2.hubspot.net/hubfs/1629777/Chatb ots\%20101.pdf?t=1526138378633

15. What is a chatbot and how to use it for your business. URL: https://medium.com/swlh/ what-is-a-chatbot-and-how-to-use-it-for-yourbusiness-976ec2e0a99f

16. Chatbot tips for businesses. URL: https://chatbotsmagazine.com/10-chatbot-tipsfor-businesses-894b39be34f4

$17.80 \%$ of businesses want chatbots by 2020 . Business Insider. URL: https://www.busines sinsider.com/80-of-businesses-want-chatbotsby-2020-2016-12

\section{References}

1. Bot (program). Material from Wikipedia the free encyclopedia. URL: https://ru.wikipedia.org/wiki/\%D0\%91\%D0 \%BE\%D1\%82_(\%D0\%BF\%D1\%80\%D0\%B E\%D0\%B3\%D1\%80\%D0\%B0\%D0\%BC\%D $0 \% \mathrm{BC} \% \mathrm{D} 0 \% \mathrm{~B} 0)$

2. Mikhailov, V. A., Mikhailov, S. V. (2004). Peculiarities of the development of information and communication environment of modern society. Actualnyje problemy teoriyi communikatsiyi: coll. of sci. papers, pp. 34-52 [in Russian].

3. Pleshakov, V. A. (2009). Cybersocialization of a person in information space. Informatsiya i obrazovaniye: granitsy communikatsiy, INFO'2009: coll. of sci. papers, GornoAltajsk: RIO GAGU, p. 51 [in Russian].

4. Silaeva, V.L. (2008). Internet as a social phenomenon. Socis, No. 11, pp. 101-107. URL: http://www.isras.ru/files/File/Socis/ 2008-11/Silaeva_14.pdf

5. Modern IT technologies for business: why do companies needs bots and clouds. URL: https://www.epravda.com.ua/rus/publications /2017/03/20/622844/

6. Ushakova, G. D., Balabanova, Yu. V. (2004). Peculiarities of virtual communication through chat. Filologicheskiy zhurnal: coll. of sci. papers, iss. 12, pp. 59-61 [in Russian]. 
7. Chatbots - who are they? URL: http://thefuture.news/chatbot

8. Chatbot report 2018: global trends and analysis. URL: https://chatbotsmagazine. com/chatbot-report-2018-global-trends-andanalysis-4d8bbe $4 \mathrm{~d} 924 \mathrm{~b}$

9. Chatbots 101: building a chatbot for business with wells fargo. URL: https://chatbot sjournal.com/chatbots-101-building-a-chatbot -for-business-with-wells-fargo-85ecf03f736d

10. Reasons to have a chatbot for your business. URL: https://chatbotslife.com/reasons-to-ha ve-a-chatbot-for-your-business-59e0c7427cf2

11. The true chatbot superpower for businesses and it's not AI. URL: https://medium.com/ @ shanejketterman/chatbot-messaging-is-po werful-ai-is-hype-so-what-is-messaging-ebd0 $620 \mathrm{c} 93 \mathrm{fb}$

12. Top 10 platforms to build a chatbot for your business. URL: https://chatbotsmagazine. com/top-10-platforms-to-build-a-chatbot-foryour-business-6393ed047be7

13. Trending: how to use facebook messenger chatbot for business. URL: https://medium.com/@kris10haley/trendinghow-to-use-facebook-messenger-chatbot-forbusiness-96fe 5dac337d

14. V-Soft consulting chatbots 101. URL: https://cdn2.hubspot.net/hubfs/1629777/Chat bots\%20101.pdf?t=1526138378633

15. What is a chatbot and how to use it for your business. URL: https://medium.com/swlh/ what-is-a-chatbot-and-how-to-use-it-foryour-business-976ec $2 \mathrm{e} 0 \mathrm{a} 99 \mathrm{f}$

16. 10 Chatbot tips for businesses. URL: https://chatbotsmagazine.com/10-chatbottips-for-businesses-894b39be $34 \mathrm{f} 4$

17. $80 \%$ of businesses want chatbots by 2020 . Business Insider. URL: https://www.busines sinsider.com/80-of-businesses-want-chatbotsby-2020-2016-12

T. O. Prokopenko, Dr.Tech.Sc, accociate professor,

e-mail: t.prokopenko@chdtu.edu.ua

O. B. Oboishchyk, student

Cherkasy State Technological University

Shevchenko blvd, 460, Cherkasy, 18006, Ukraine

\section{SPECIFICS OF USING CHATBOTS FOR BUSINESS NEEDS IN MODERN MESSENGER CHATS}

The article contains the analysis of peculiarities of using chatbots for business needs on the basis of simulation of a person speech behavior in the process of communication in modern messenger chats. The definition of chatbots, their classification and major functions are considered. The nature of messenger apps together with the concept and place of messenger bots as an important tool for business needs satisfaction are disclosed. The main advantages of using the chatbot technology for meeting modern business needs are reviewed. Judging by the emerging trends in the development of an online chatbot service, a hypothesis is put forward in the article that the market for tools using artificial intelligence and chatbots in the business needs satisfaction sector will only grow. It has been analyzed that the universal interactive systems combining the services of virtual and real consultants in one window will obviously be improved and used more and more widely by various market players in the nearest future. Following the integration within the chat of a virtual consultant with the human operator, it is assumed in the article that we can expect the integration of the online service with the internal systems of different types of businesses. It is hypothesized that this will allow to take into account the client's profile in its entirety and integrity in the dialogue process, increase the targeting of recommendations and proposals. Conclusions about the possibility and expediency of using various types of chatbots for business needs in modern instant messenger chats are made. The generalized chatbots classification which will ensure the possibilities of the necessary chatbot choice for business tasks solution and allow to achieve the planned results for efficient company work is proposed.

Keywords: chatbot, bot, messenger chat, artificial intelligence, classification, business needs. 